NBER WORKING PAPER SERIES

\title{
FURTHER EVIDENCE THAT LEGALIZED ABORTION LOWERED CRIME: A REPLY TO JOYCE
}

John J. Donohue III

Steven D. Levitt

Working Paper 9532

http://www.nber.org/papers/w9532

NATIONAL BUREAU OF ECONOMIC RESEARCH

1050 Massachusetts Avenue

Cambridge, MA 02138

February 2003

The views expressed herein are those of the author and not necessarily those of the National Bureau of Economic Research.

C2003 by John J. Donohue III and Steven D. Levitt. All rights reserved. Short sections of text not to exceed two paragraphs, may be quoted without explicit permission provided that full credit including @notice, is given to the source. 
Further Evidence that Legalized Abortion Lowered Crime: A Reply to Joyce

John J. Donohue III and Steven D. Levitt

NBER Working Paper No. 9532

February 2003

JEL No. K42, I38, J13

\section{$\underline{\text { ABSTRACT }}$}

Donohue and Levitt (2001) present a number of analyses that suggest a causal link between legalized abortion and reductions in crime almost two decades later when the cohorts exposed to legalized abortion reach their peak crime years. Joyce (2003) challenges that finding. In this paper, we demonstrate that Joyce's failure to uncover a negative relationship between abortion and crime is a direct consequence of his decision to focus exclusively on the six-year period 1985-90 without including adequate controls for the crack epidemic. We provide empirical evidence that crack hit the high-abortion early legalizing states harder and earlier. We then demonstrate that using precisely the same treatment and control groups as Joyce, but extending the data analysis to encompass the lifetime criminal experiences (as opposed to an arbitrary six-year window), the evidence strongly supports the hypothesis that legalized abortion reduces crime. We also show that our original results are robust to focusing on only the cohorts born immediately before or after Roe v. Wade. The data suggest that ease of access to abortion, rather than simply de jure legalization, is a critical determinant of the extent of the crime reduction.

John J. Donohue III

School of Law

Stanford University

Stanford, CA 94305-8610

and NBER

jjd@stanford.edu
Steven D. Levitt

Department of Economics

University of Chicago

1125 East $59^{\text {th }}$ Street

Chicago, IL 60637

and NBER

slevitt@midway.uchicago.edu 


\begin{abstract}
$\underline{\text { Abstract }}$
Donohue and Levitt (2001) present a number of analyses that suggest a causal link between legalized abortion and reductions in crime almost two decades later when the cohorts exposed to legalized abortion reach their peak crime years. Joyce (2003) challenges that finding. In this paper, we demonstrate that Joyce's failure to uncover a negative relationship between abortion and crime is a direct consequence of his decision to focus exclusively on the six-year period 198590 without including adequate controls for the crack epidemic. We provide empirical evidence that crack hit the high-abortion early legalizing states harder and earlier. We then demonstrate that using precisely the same treatment and control groups as Joyce, but extending the data analysis to encompass the lifetime criminal experiences (as opposed to an arbitrary six-year window), the evidence strongly supports the hypothesis that legalized abortion reduces crime. We also show that our original results are robust to focusing on only the cohorts born immediately before or after Roe v. Wade. The data suggest that ease of access to abortion, rather than simply de jure legalization, is a critical determinant of the extent of the crime reduction.
\end{abstract}

In Donohue and Levitt (2001), we advanced the hypothesis that the legalization of abortion 
in the 1970's is causally related to the decline in crime experienced in the United States in the 1990s. We are delighted to have researchers probe the robustness of our initial findings, and indeed, a number of researchers have confirmed the link between abortion legalization and crime that we first identified (Leigh and Wolfers 2000; Reyes 2002; Sen 2002; Sorenson, Wiebe, and Berk 2002). In contrast to these papers, Joyce (2003) reports findings which he interprets as evidence against a causal link between abortion and crime.

In this reply, we demonstrate that none of the five primary arguments that Joyce makes in his paper poses a serious challenge to our hypothesis. His claim that legal abortions simply replaced illegal abortions is shown to be directly at odds with the existing evidence. Many of his empirical findings are revealed to simply be an artifact of his puzzling decision to focus his analysis on the small subset of the data which coincides with the peak of the crack epidemic (without including controls for crack in the regressions). We present evidence that crack hit early legalizing, high abortion states earlier and harder than the rest of the country. We then demonstrate that if one simply takes Joyce's identification strategy regarding the early legalizing states, but follows these same cohorts over their entire lifetime rather than just the six-year window 1985-90, abortion exposure is indeed associated with lower criminal involvement. Finally, we show that Joyce's claims about the sensitivity of our results to using particular subsets of the data are inaccurate. The divergence between his results and ours arises not because of the subset of data used, but rather, differences in the source of identification. Joyce identifies his estimates off of national time series variation. When we instead use within-state variation over time on these same subsets, our original results prove robust.

The remainder of the paper is structured as follows. Section I briefly summarizes the basic findings from our earlier work that led us to advance the hypothesis that abortion legalization 
can lower crime, and underscores that Joyce has not directly challenged any of those findings.

Section II then lays out the five primary pieces of evidence that Joyce (2003) presents as evidence against an impact of legalized abortion on crime. In responding to these points, we demonstrate that in each case the inference drawn by Joyce is likely to be false and that these new and different sources of identification that Joyce highlights yield further support to the initial hypothesis of Donohue and Levitt (2001). Section III offers some concluding comments.

\section{The Link between Abortion Legalization and Crime}

Donohue and Levitt (2001) present five pieces of evidence consistent with the hypothesis that cohorts born after the legalization of abortion have lower crime rates because legalized abortion reduces the number of unwanted children, who are at higher risk of engaging in criminal conduct when they grow up. First, the five states that legalized abortion in roughly 1970 (as opposed to the national legalization resulting from the January 1973 U.S. Supreme Court decision in Roe v. Wade) experienced a somewhat earlier drop in crime. Second, higher abortion states (based on the rates of legal abortion in the 1970s) showed much greater drops in crime during the 1985 - 1997 period. In contrast, the crime trends in high and low abortion states were similar over the period from 1973-1985, when the children born after legalization were too young to be influencing crime rates. Third, this relationship between more legal abortions in the 1970s and lower crime over the period 1985 - 1997 persisted in panel data regression models that controlled for prisoners and police per capita, state economic conditions, and state and year fixed effects. This result was also robust to controls for cross-state mobility, the effects of immigration, and various deletions of potentially idiosyncratic states (including New York and California). Fourth, the link between abortion and crime was only present for those born after legalization (roughly 
those under age 25 when our arrest data ends in 1998), and not for those older than 25 as of 1998 (and therefore born prior to Roe v. Wade). Figure 1 shows that, for the period 1985-1998, arrest rates for those under 25 fell more (or rose less) as one moves from the states with the lowest abortion rates to those with the middle level of abortion rates to those with the highest level of abortions. Figure 2 reveals, however, that the link between higher rates of abortion and lower rates of crime is not observed in these groupings if one limits the focus to those over age 25 , who were overwhelmingly born at a time when abortion was illegal. In this second figure, there is no discernible relationship between the rate of abortion and changes in arrests. Fifth, the pattern of lower rates of crime in states with higher rates of abortion held true when we linked the abortion rates in a particular state in a particular year with the crime committed by the cohort born in that year, even controlling for state-year specific interactions.

\section{Joyce's Five Primary Arguments}

Joyce does not challenge any of these findings directly, and indeed, confirmed a number of them in previously circulated drafts of his paper (Joyce 2001). Rather, Joyce presents five different arguments as to why he believes the link between legalized abortion and crime is not causal:

(1) He claims that demographers have concluded that most legal abortions in the early 1970's replaced illegal abortions. Since no one has data on illegal abortion rates, the results in Donohue and Levitt (2001) may be spurious. (Page 1 of Joyce)

(2) For the six-year period 1985-90, there is no measurable impact of state abortion rates on state crime rates; only after 1991 does the strong negative relationship between abortion and crime emerge. (Tables 1 and 3 of Joyce) 
(3) States that legalize abortion in 1970 experience initial reductions in crime consistent with a causal impact of legalized abortion, but the fact that these early legalizers continue to experience greater reductions in crime even after abortion becomes legal nationwide argues against causality. (Table 2 of Joyce).

(4) A comparison of cohorts born just before or after the early legalizations in 1970 in legalizing and non-legalizing states does not yield negative impacts of abortion on crime for the years 19851990. (Table 4 of Joyce)

(5) In states where abortion only became legal in 1973 with the passage of Roe $v$. Wade, those born after legalization do not have systematically lower crime rates than those born before. (Note, however, that Joyce makes no distinction between states with high abortion rates versus those with low abortion rates. It is identified only from national time-series variation in crime rates.) (Table 5 of Joyce)

We address these five points in turn.

Joyce Claim 1: Demographers have concluded that most legal abortions in the early 1970's replaced illegal abortions. Since no one has data on illegal abortion rates, the results in Donohue and Levitt (2001) may be spurious.

It is true, and for obvious reasons, that no one has good data on the number of illegal abortions. Both theory and evidence, however, strongly suggest that the prevalence of abortion rose sharply after legalization. From a theoretical perspective, there is no question that the dollar cost, the medical risk, and the taint associated with engaging in illegal conduct fell after legalization, all of which would lead to higher rates of abortion. With respect to the dollar cost, Kaplan [1988, p. 164] notes that "an illegal abortion before Roe v. Wade cost $\$ 400$ to $\$ 500$, while today, thirteen years after the decision, the now legal procedure can be procured for as little as 
\$80." ${ }^{\prime \prime}$ Empirically, if legal abortions simply replaced illegal ones, it is hard to understand why it took seven years after Roe for the number of legal abortions to reach a steady state. The number of legal abortions more than doubled between 1973 and 1980. Michael (1999) using self-reported data on pregnancy outcome histories finds abortion rates to be roughly an order of magnitude higher after legalization. Thus, the first pre-requisite for legalization to have an impact on crime is met -- legalization increased the rate of abortion. Consistent with this finding is a dramatic decline in the number of children put up for adoption after abortion became legal. According to Stolley (1993), almost 9 percent of premarital births were placed for adoption before 1973; that number fell to 4 percent for births occurring between 1973 and 1981.

The increase in abortions, however, does not generate a one-for-one decline in fertility since the availability of legalized abortion is likely to lead to an increase in unintended pregnancies. This moral hazard effect, as well as the replacement effect of illegal abortions, are both factors that would cause the number of legal abortions to overstate the reduction in unwanted births caused by legalization. Of course, the ability to improve the timing and circumstances of births means that abortion improves birth and life outcomes even when it does not lower the total number of births. A woman who has an abortion after being raped, and who then gives birth following a wanted pregnancy is improving the life chances of her child. As long as the number of unwanted births falls, even if total births falls by a smaller amount, one would expect to see better life outcomes on average for the resulting cohorts. Accordingly, our measure of legalized abortion is not a perfect measure of the improved life prospects of the post-legalization birth cohort with

${ }^{1}$ Kahane (2000) documents that the number of abortions is quite responsive to the price, so on that basis alone one would predict substantial jumps in the number of abortions after legalization. 
some factors tending to overstate and some tending to understate the true effect that we are trying to capture.

Given the imperfections of the abortion rate as a proxy, under standard conditions one expects this measurement problem will tend to bias downward the magnitude of the estimated effect of abortion on crime. Indeed, after our initial paper was published, Stanley Henshaw of the Alan Guttmacher Institute provided us with better abortion data which reported abortion rates by the state of residence of the birth mother, as opposed to the state where the abortion was performed. In Table 1 we report estimates of the original specifications presented in Donohue and Levitt (2001) using these two different abortion proxies. The first column of the table is the coefficient on the abortion proxy based on the state in which the abortion is performed; the second column employs the improved abortion proxy using mother's state of residence. Each row of the table represents a different dependent variable, specification, or sample. Importantly, in every case, the coefficients becomes more negative when the better proxy is used. Indeed, the coefficients in column 2 are 40 percent larger in magnitude on average than the coefficients in column 1. This is powerful evidence that we are capturing a real effect, since using more precise abortion data would not be expected to improve the estimates in such a uniform fashion if the abortion effect were spurious. Throughout the remainder of this paper we rely on the more precise abortion data.

Using the better abortion proxy has the same impact on the specifications used by Joyce, and indeed, many of his null findings regarding abortion disappear when the better data are used. For instance, with respect to the cohorts born after 1973 in Joyce's Table 1b, he finds no impact of abortion on arrest rates in this sub-sample, but when we run those precise regressions using the better abortion data, we obtain negative coefficients on all three crime categories. Furthermore, 
when we extend the arrest rate data through 1998, two of the three coefficients become negative and statistically significant.

Finally, we were quite surprised that Joyce would argue that legalization had no impact on the composition of births given that some of his own previous research provides some of the most compelling evidence for the impact of abortion legalization on birth outcomes through precisely the channel we hypothesize. In Joyce (1985), a paper entitled "The Impact of Induced Abortion on Birth Outcomes in the U.S.", Joyce used state level abortion rates after legalization as a covariate to explain health outcomes of babies, finding that "by reducing the number of unwanted births, abortion enhances the healthiness of newborns of a given weight and gestational age, as well as improving the distribution of births among high-risk groups." In other words, the legalization of abortion reduces unwanted births and improves the life prospects of cohorts born after legalization by increasing the chance that they are healthy and wanted by their mothers. Indeed, in a 1987 published paper, Joyce underscored this point:

"The findings from this study support the contention that by preventing unwanted births, abortion reduces the percentage of preterm and low-weight infants. Few would argue that averting unintended pregnancies is the most preferable strategy for reducing unwanted births. However, until family planning is more widely practiced, especially among women of low socioeconomic status, abortion will remain an important option for many pregnant women. According to the estimates from the study, legislative attempts to ban abortion would have a negative impact on birth outcomes." (Joyce, 1987: 241.)

Hence, if legalizing abortion has a positive effect on birth outcomes then 1) legal abortions cannot be simply replacing formerly illegal abortions, and 2) it should not be surprising that legalizing abortion would have a positive effect on life outcomes such as criminal activity as well.

Joyce claim 2: For the six-year period 1985-90, there is no measurable impact of state abortion rates on state crime rates; only after 1991 does the strong negative relationship between 
abortion and crime emerge.

Joyce examines the six-year period from 1985 through 1990 and claims that the link between abortion rates and crime is not evident in this period. These years correspond almost exactly to a spike in violence typically attributed to crack cocaine. The data suggest that the impact of crack was extremely heterogeneous geographically and demographically, with the effects concentrated on youths (especially minorities) in large urban centers. Thus, the cohorts most directly affected by crack are those born immediately after abortion legalization. Because residents in the early legalizing states of California and New York are disproportionately minorities who reside in large cities, failure to control for crack is likely to induce a bias against finding a crime-reducing impact of legalized abortion.

Unfortunately, the crack epidemic has not proven amenable to easy quantification. Without good data for each state, year, and cohort on the criminogenic influence of crack, any regression model will have a serious omitted variable problem during the major crack epidemic of the late 1980s that caused dramatic crime increases. Given the magnitude of the shock associated with crack (youth homicide rates more than doubled in a five year period), any effects of legalized abortion could be easily swamped. Thus, Joyce pins much of his argument against an effect of abortion legalization on crime by focusing on exactly the period when crime regression models will have the hardest time teasing out any effect on crime. ${ }^{2}$

2 Indeed, even a statistically significant impact of incarceration on violent crime and homicide - an extremely robust result in the literature - disappears in Joyce's regressions on the 1985-90 period. In contrast, for the full 1985-97 time period that Donohue and Levitt use, the estimated impact of incarceration on homicide and violent crime is highly statistically significant. A similar pattern emerges regarding the impact of police on crime. Over the whole sample the coefficient on police is negative and statistically significant. For the period 1985-90, the police coefficient is positive. 
Figure 3, which depicts the rate of drug-related homicides from 1976-99 in the early legalizing states relative to the rest of the country, provides empirical evidence substantiating the conjectures of the previous paragraph. Throughout the time period, the early legalizing states have a higher rate of drug-related homicides. Over the period 1985 - 1990, drug-related homicides increase everywhere, but the gap between the states that legalized abortion in 1970 and the rest of the country grows prominently. The year 1990 represents the point at which the gap in drug homicides between early legalizers and the rest of the nation is greatest - more than four times the magnitude of the gap in the early 1980s and the late 1990s.

If the crack epidemic is a temporary phenomenon in the late 80 s and early 90 s that hits the high abortion, early legalizing states more severely, then regression estimates that fail to adequately control for crack will be biased against finding a causal impact of legalized abortion for the years 1985-90 and will be biased in favor of legalized abortion in the latter period as the epidemic subsides. That story is completely consistent with the pattern of results in Joyce's Table 1.

It is widely believed that the impact of crack was concentrated on homicide and violent crime, and much smaller for property crime. The results in Joyce's Table 1 show that legalized abortion was associated with drops in property crime, even during the $1985-90$ period. This finding is once again consistent with Joyce's results being driven by crack as an omitted variable,

Finally, it should be emphasized that the effective abortion rate (the key explanatory variable in Joyce Table 1a) tends to be quite low during the period from 1985-1990, particularly for violent crime and murder. ${ }^{3}$ Indeed, Joyce acknowledges that the effective abortion rate for

3 The "effective abortion rate" is a weighted average of the abortion rates for a particular state that would be expected to influence crime in that state in a particular year, where the weights 
murder was only 8 per 1000 live births between 1985 and 1990 - roughly one-twentieth the level reached by 1997 , and one-fortieth of the steady-state level once all potential criminals are born after legalized abortion. Thus, in addition to the other problems associated with the 1985-90 period, Joyce's estimates of the effect of abortion on crime are being identified off of very small amounts of variation relative to the latter part of the sample.

Joyce claim 3: States that legalized abortion in 1970 experienced initial reductions in crime consistent with a causal impact of legalized abortion, but the fact that these early legalizers continued to experience greater reductions in crime even after abortion becomes legal nationwide argues against causality.

In trying to estimate the effect of abortion legalization on crime, we focused on two defining legal events - five states initially legalized abortion in 1970 (Alaska, California, Hawaii, New York, and Washington), and then the Supreme Court effectively legalized abortion throughout the rest of the country in January of $1973 .{ }^{4}$

are based on the proportion of crime committed by individuals of a particular age. The concept is needed to provide a single measure of how abortion legalization would be expected to influence crime in a certain state in a certain year. Thus, in computing the 1990 effective abortion rate for a state that legalized abortion in 1970, one would take the weighted average abortion rate for all abortions between 1970 and 1989 weighted by the proportion of crimes committed by each individual age from 1 to 20. (Obviously, since 20 year olds commit a good deal of crime while 1 year olds commit none, the contribution of the abortion rate in 1970 to the effective abortion rate is high, while that of the abortion rate in 1989 is zero.)

${ }^{4}$ Unlike previous scholars, Joyce includes the District of Columbia as an early legalizer on the basis of a 1974 book by Lawrence Lader, entitled: "Abortion II: Making the Revolution." Lader does indeed claim that the District Court decision in U.S. v. Vuitch "made Washington the first area in the country where abortion was completely legalized." (P.111.) U.S. v. Vuitch, 305 F. Supp. 1032 (Dist. D.C. 1969) involved a doctor who was indicted for performing an abortion in violation of the D.C. statute that made it a felony to perform an abortion, unless it was done (1) for the preservation of the mother's life or health, and (2) under the direction of a competent licensed 
Joyce's Table 2 confirms that crime dropped relative to other states for cohorts born in early legalizing states. His regression also suggests that the birth cohorts born in early legalizing states in the years after 1973 seem to show even greater drops in crime, which Joyce takes as evidence against our hypothesis, but only because he fails to understand the hypothesis that we put forth.

Joyce's implicit assumption is that the sole determinant of the impact of legalized abortion is simply whether abortion is legal. Since after 1973 abortion is legal everywhere Joyce posits that the post-1973 birth cohorts should show similar rates of crime between the early legalizing states and other states. Our original hypothesis, however, was based on a view that the mere act of abortion legalization is not sufficient to equalize the costs (financial, social, and psychological) of abortion across time and place. Rather, our model argues that abortion rates as a fraction of live births is a better proxy for the impact of legal abortion than is the dichotomous indicator of legal status. And, indeed, in our earlier paper, we demonstrate that the gap in abortion rates between the early legalizers and other states actually grows over time, even though abortion becomes legal everywhere in 1973. Table 2 shows the effective abortion rates for violent crime for the early legalizer and other states at selected points in time. In 1988, the early legalizers had an effective abortion rate that was 54 (per 1000 live births) higher than in other states, but that this difference

practitioner of medicine. The trial court in Vuitch held that the first exception was unconstitutionally vague as the term "health" was ambiguous, and the burden was on the doctor to show that an abortion was necessary for the mother's life or health. (It also held that the statute was severable and that the second exception remained valid despite the invalidity of the first exception.) While this was obviously a pro-legalization decision, it was a decision of a lower court and it was quickly overturned on appeal by the United States Supreme Court in the case of U.S. v. Vuitch, 402 U.S. 62 (U.S. 1971), which upheld the DC abortion law. Consequently, the most comprehensive assessment of the various changes in abortion law - Merz, Jackson, and Klerman (1995) - doesn't even mention the Vuitch case, and the other scholars who have written in this area have not included DC as an early legalizer. 
grew to 151 in 1994 and then to 186 in 1997.

Thus, when Joyce finds in his Table 2 that the gap in crime continues to widen between early legalizing and all other states after 1973, he presents evidence that exactly coincides with the prediction of our original hypothesis. We take this as compelling evidence in support of our theory (even though he construes this as evidence against his misconception of what our theory is, or perhaps what he thinks it should be). ${ }^{5}$

Joyce claim 4: A comparison of cohorts born just before and after 1970 (when the early legalizing states legalized) in early legalizing and non-legalizing states does not yield negative impacts of abortion on crime for the years 1985-1990.

In Table 4 of his paper, Joyce attempts to identify the impact of legalized abortion on crime by exploiting the fact that a subset of states legalized in 1970, three years before Roe v. Wade. By comparing the crime rates of individuals born in the years immediately before and after 1970 in states that did or did not legalize early, one can generate a "differences-in-differences" estimate of the impact of legalization on crime.

The idea is a sensible one, modeled directly after the identification strategy of Gruber et al. (1999). In actually carrying out his analysis, however, Joyce makes a very puzzling choice: rather than looking at the lifetime criminal involvement of individuals born in the years surrounding

5Joyce's Table 2 confirms that crime fell more in repeal states relative to non-repeals states for cohorts born in 1971-1973, even though his definition of the states in these categories as well as the comparison dates are both imperfect. Specifically, the "control" is for cohorts born from 1968-70 (even though legalization had occurred in 1970 in the "repeal" states) and the preRoe "repeal" years are taken as 1971-1973 (even though Roe was decided in January of 1973). Remember that Joyce includes DC as a repeal state because of a 1969 decision, and the other early legalizations came in 1970, so the controls and treatments are muddied in both 1970 and in 1973 when abortion was legalized everywhere for virtually the entire year. 
1970, he only looks at the crimes they commit in the years 1985-1990. For those years, he finds no evidence of a drop in crime for the treatment group exposed to legalized abortion.

Joyce's decision to limit his analysis to the period $1985-1990$ is quite curious. First, it is hard to understand what the possible benefit could be of discarding the data for the decade of the 1990's, which represents the majority of the available data. Second, as we argued above, the years 1985-1990 are precisely the period in which crack was differentially impacting the early legalizing states, especially New York and California. The first cohort exposed to legalized abortion reached their teenage years at precisely the time when the crack epidemic got started.

Table 3 demonstrates how radically different the conclusions are if one carries out the same exercise, looking not just at a six-year period in their teens, but at criminal involvement of these cohorts throughout their whole life. Using homicide data from the FBI's Supplemental Homicide Reports, we present simple differences-in-differences estimate. Following the same logic as Joyce, we divide states into control states that do not legalize until Roe v. Wade in 1973 (columns 1 and 2) and treatment states that legalize abortion in 1970 (columns 4 and 5). Cohorts born in 1967, 1968, and 1969 (columns 1 and 4) are unexposed in all states. The cohorts born in 1971, 1972, and 1973 (columns 2 and 5) are exposed only in the treatment states. ${ }^{6}$ We report percent changes in crime across the cohorts in columns 3 and 6 . The differences-in-differences

6 The portion of the cohort born in treatment states in the latter part of 1973 were technically exposed to legalized abortion, although actual abortion rates in the immediate aftermath of Roe v. Wade were extremely low. The age groups Joyce analyzes also suffer from imprecision in classification of exposure to legalized abortion (i.e. some members of "exposed" cohorts are unexposed and vice-versa). The results are not sensitive to minor variations in the choice of cohorts.

In order to simplify the exposition, we present our results in a slightly different manner than Joyce's Table 4, but the source of identification identifying our estimates in Table 3 and Joyce's Table 4 are the same. 
estimates of abortion exposure, which are the key findings of the table, are presented in column 7. The top three rows of the table report the raw number of homicides committed by the relevant samples for three age groups: under 15 years old, 15-19 years old, and 20-26 years old. The fourth row reports the total homicides from ages 0 to 26 .

Beginning with the homicides committed by those under the age of 15 in the top row, the number of homicides committed by those born in control states in 1971, 1972, and 1973 is 13.6 percent higher than the number committed by those born in control states in 1967, 1968, and 1969 (360 homicides versus 317). This suggests that factors other than legalized abortion (which did not affect any of these cohorts in the control states) were causing an increase in homicide rates. In the early legalizing states, the cohorts born after legalization also commit more homicides before age 15 , but the number is only 4.1 percent greater than that for the earlier cohorts. Thus, the differences-in-differences estimate of exposure to legalized abortion is a 9.5 percent reduction in homicide before age 15 .

The second row of the table corresponds to homicides committed between the ages of 15 to 19. Note that these ages correspond closely to the time period 1985-90 which Joyce's Table 4 analyzes. For both treatment and control groups, there is an enormous increase of 65 percent in homicides for the later cohort. This result corroborates the well documented fact that youth homicide skyrocketed in the late-1980s. For this six-year period, the differences-in-differences estimates in column 7 confirm the absence of a measured impact of legalized abortion on crime reported in Joyce's Table 4.

The third row of the table, which looks at homicides from ages 20-26, demonstrates a large estimated impact of abortion exposure. In control states, homicide rises by 11.6 percent for the later cohort. In contrast, homicide falls 8.6 percent in the early legalizing states, yielding a 
differences-in-differences estimate of abortion exposure of -20.2 percent.

Looking over the entire life of these cohorts through age 26 (the oldest age of data available for all cohorts), the differences-in-differences estimate of exposure to legalized abortion is -12.5 percent. Thus, just as our theory would predict, homicide was lower among those exposed to abortion. The results in Joyce's Table 4 are simply an aberration of looking at a narrow time window in which crack biases the estimates. Although not shown in tabular form, we obtain similar results when carrying out a parallel analysis on arrest data for violent crime, property crime, and homicide. ${ }^{7}$ The differences-in-differences estimates of exposure to legalized abortion using the arrest data range from a 6-17 percent reduction in arrests, depending on the crime category. These findings confirm that the "natural experiment" associated with early legalization in a subset of states provides further evidence in favor of our original hypothesis.

Joyce claim 5: In states where abortion only became legal in 1973 with the passage of Roe v. Wade, those born after legalization do not have systematically lower crime rates than those born before. (Note, however, that Joyce makes no distinction between states with high abortion rates versus those with low abortion rates. It is identified only from national time-series variation in crime rates.)

Joyce's final challenge to our initial hypothesis is presented in Table 5 of his paper. In that

7 Shortcomings of the arrest data limit the analysis to ages 0-24, since single-year of age arrest data are not available for those 25 and older. Moreover, because the arrest data we are using do not indicate the month in which the arrest occurs (the Supplemental Homicide Report data does have this information), there is greater imprecision in attaching arrests to a particular cohort (i.e. a 16 year-old arrested in January 1990 and a 16 year-old arrested in December 1990 were likely to have been born in different years, but there is no way to distinguish between them in the arrest data). 
table, Joyce compares the crime rates of those born in the years immediately prior to Roe and the years immediately after. Early legalizing states are excluded from the analysis. He finds that the number of crimes committed between the ages of 18 and 22 (as well as 20 - 24) was somewhat higher among those individuals born in 1974-76.

There are three important points to make about this analysis. First, these estimates are identified from national time-series trends. ${ }^{8}$ The comparison made is simply between those born before and after legalization. Any factor (such as crack) which is correlated with abortion rates and differentially affected the propensity to commit crime across ages or cohorts during the time period he examines will bias his estimates. The analysis does not differentiate between states in which it was very easy to get abortions after legalization (e.g. Kansas had 414 abortions per live birth in 1973) and states where it remained quite difficult (e.g. not a single legal abortion was performed in North Dakota or Louisiana in 1973 in spite of de jure legalization). Second, Joyce once again inexplicably limits his analysis to just a few years of the lives of these cohorts, rather than using all of the available data.

Given the dramatic aggregate fluctuations in youth crime rates that were observed during this time period and the plausible alternative explanation (crack), a more direct and believable approach to identifying the impact of legalized abortion on crime uses within-state or even withinstate and within-age variation over time. Thus, we estimate specifications of the following form

$$
\ln \left(\text { Crime }_{\mathrm{csy}}\right)=? \text { Abort }_{\mathrm{cs}}+?_{\mathrm{c}}+?_{\mathrm{sa}}+?_{\mathrm{y}}+?_{\mathrm{cst}}
$$

where $c, s, y$, and $a$, represent cohort of birth, state, year, and age respectively. The variable

${ }^{8}$ The line of argument that the national time-series trends are not supportive of the abortion argument in this time period is not new, having been previously presented by both Sailer (1999) and Cook and Laub (2001). 
Crime captures either arrests in a particular crime category, or homicides from the Supplemental Homicide Reports; Abort is the number of legal abortions per live birth that a particular cohort was exposed to in utero. Because of the richness of the data (the variation is at the level of statecohort-year, rather than simply state-year), we are able to control for national cohort effects, national year effects, and (in some specifications) state-age interactions in crime rates. ${ }^{9}$ Unlike the estimates in Joyce's Table 5, our estimate of ? is identified off of within-state (and even within state and age) variation over time in abortion exposure.

The results of estimating equation (1) for the same cohorts used in Joyce's Table 5 (those born 1968-1976) are presented in Table $4 .{ }^{10}$ For each of the three arrest categories, as well as homicide offending rates (based on supplemental homicide report data), we present the abortion coefficient from two different specifications: one with state and age fixed-effects and the other with state-age interactions. Only the coefficient on the abortion rate measure is reported in the table. In every specification, the abortion variable carries a negative coefficient, as predicted by our theory. The estimates are statistically different from zero in six of the eight columns. Indeed, the coefficients are larger in absolute magnitude than those obtained using the full-sample of all cohorts from all states presented in Table 7 of Donohue and Levitt (2001). Thus, there is no support for Joyce's claim that our results are sensitive to focusing on the set of cohorts born just before and after Roe, or that our results are dependent on including the early legalizing states in the analysis (early legalizing states are excluded in Table 4). Rather, the difference between our results and Joyce's Table 5 hinge critically on the fact that his identification is driven by national-

9 This specification mirrors the one used in Donohue and Levitt (2001), Table 7.

10 Similar results are obtained when the sample is further limited to the cohorts 19711976, or when the cohort 1973 is dropped. 
time series variation in a period of sharply rising youth crime rates that coincides with the crack epidemic.

\section{Conclusion}

Joyce's article has suggested a number of interesting identification strategies for testing a causal relationship between legalized abortion and crime. In our reply, we demonstrate that the differences between our earlier findings and Joyce's results are not due principally to his identification strategies, but rather, to his exclusive focus on the six-year period in which the crack epidemic was most virulent. We present evidence supporting the claim that crack hit the states that legalized abortion in 1970 harder than the rest of the country. Because of the influence of crack on crime for a particular time segment, it is important to look at the whole period for which data are available (as opposed to inexplicably and arbitrarily limiting the sample to the period 1985-90). When we do just that, using the same sources of variation as Joyce, legalized abortion is once again strongly associated with reductions in crime. Finally, we demonstrate that Joyce's claim that our results do not hold for the cohorts born immediately before and after Roe is the consequence of his identification strategy of using national time-series variation in a period of sharply rising youth crime rates coinciding with the crack epidemic. Looking within states over time, the negative relationship between abortion exposure and crime emerges even more strongly in the cohorts born immediately before and after Roe than it does in the sample as a whole. Thus, we find nothing in Joyce's paper that offers a serious challenge to the original hypothesis proposed in Donohue and Levitt (2001). Indeed, the results we present in this reply represent some of the strongest evidence to date in favor of the hypothesis that abortion legalization has dampened crime. 


\section{$\underline{\text { References }}$}

Cook, Philip, and John Laub, 2001, "After the Epidemic: Recent Trends in Youth Violence in the United States," NBER Working Paper No. 8571.

Donohue, John, and Steven Levitt, 2001, "Legalized Abortion and Crime", Quarterly Journal of Economics 116 (2): 379-420.

Gruber, Jonathan, Phillip Levine, and Douglas Staiger, 1999, “Abortion Legalization and Child Living Circumstances: Who is the 'Marginal Child?'” Quarterly Journal of Economics, CXIV: 263-291.

Joyce, Theodore, 1985, "The Impact of Induced Abortion on Birth Outcomes," NBER Working Paper No. 1757.

Joyce, Theodore, 1987, "The Impact of Induced Abortion on Black and White Birth Outcomes in the United States,"Demography, Vol. 24, Issue 2, (May), 229-244.

Joyce, Theodore, 2003, “Did Legalized Abortion Lower Crime?" Journal of Human Resources, 38(1): $1-37$.

Kahane, Leo H., 2000, "Anti-Abortion Activities and the Market for Abortion Services: Protest as a Disincentive," American Journal of Economics and Sociology, 59(3): 463-80.

Kaplan, John, 1988, “Abortion as a Vice Crime: A 'What if' Story,” Law and Contemporary Problems, LI: 151-179.

Lader, Lawrence, 1974, Abortion II: Making the Revolution, New York: Beacon.

Leigh, Andrew, and Justin Wolfers, 2000, “Abortion and Crime," AQ: Journal of Contemporary Analysis, 72(4): 28-30.

Merz, JF, CA Jackson, JA Klerman, 1995, “A Review of Abortion Policy: Legality, Medicaid Funding, and Parental Involvement, 1967-1994,” Women's Rights Law Reporter 17: 1-61.

Michael, Robert, “Abortion Decisions in the U.S.," unpublished manuscript, University of Chicago, 1999.

Reyes, Jessica Wolpaw, 2002, “The Impact of Childhood Lead Exposure on Crime,” Unpublished paper, Harvard Department of Economics. 
Sailer, Steven, 1999, “Does Abortion Prevent Crime?” Slate Magazine, August 23, 1999.

Sen, Anindya, 2002, "Does Increased Abortion Lead to Lower Crime? Evaluating the Relationship between Crime, Abortion, and Fertility," Unpublished paper, University of Waterloo Department of Economics

Sorenson, Susan, Douglas Wiebe, and Richard Berk, 2002, "Legalized Abortion and the Homicide of Young Children: An Empirical Investigation," Analyses of Social Issues and Public Policy 2(1): 239-256.

Stolley, K.S., 1993, "Statistics on adoption in the United States," The Future of Children: Adoption, 3(1): 26-42. 
Table 1: Estimates of the Impact of Abortion on Crime with Different Abortion Rate Measures

\begin{tabular}{|c|c|c|}
\hline & \multicolumn{2}{|c|}{ Abortion Proxy: } \\
\hline $\begin{array}{l}\text { Specification and dependent } \\
\text { variable: }\end{array}$ & $\begin{array}{l}\text { Abortions by state where } \\
\text { procedure performed } \\
\text { (noisier proxy, used in original } \\
\text { Donohue and Levitt paper) }\end{array}$ & $\begin{array}{l}\text { Abortions by state of residence of } \\
\text { birth mother } \\
\text { (better, newly available proxy) }\end{array}$ \\
\hline \multicolumn{3}{|l|}{$\begin{array}{l}\text { ln (state crime rates) } \\
\text { (includes criminals of all ages) }\end{array}$} \\
\hline Violent crime & $\begin{array}{l}-0.129 \\
(0.024)\end{array}$ & $\begin{array}{l}-0.153 \\
(0.030)\end{array}$ \\
\hline Property crime & $\begin{array}{l}-0.091 \\
(0.018)\end{array}$ & $\begin{array}{l}-0.112 \\
(0.018)\end{array}$ \\
\hline Homicide & $\begin{array}{l}-0.121 \\
(0.047)\end{array}$ & $\begin{array}{l}-0.166 \\
(0.055)\end{array}$ \\
\hline \multicolumn{3}{|c|}{$\begin{array}{l}\ln (\text { arrest rates under age } 25) \text { minus } \\
\ln \text { (arrest rates over age } 25)\end{array}$} \\
\hline Violent crime & $\begin{array}{l}-0.062 \\
(0.034)\end{array}$ & $\begin{array}{l}-0.107 \\
(0.041)\end{array}$ \\
\hline Property crime & $\begin{array}{l}-0.063 \\
(0.019)\end{array}$ & $\begin{array}{l}-0.092 \\
(0.024)\end{array}$ \\
\hline Homicide & $\begin{array}{l}-0.137 \\
(0.046)\end{array}$ & $\begin{array}{l}-0.179 \\
(0.070)\end{array}$ \\
\hline \multicolumn{3}{|c|}{$\ln$ (arrest rates by single year of age) } \\
\hline Violent crime & $\begin{array}{l}-0.028 \\
(0.004)\end{array}$ & $\begin{array}{l}-0.043 \\
(0.007)\end{array}$ \\
\hline Property crime & $\begin{array}{l}-0.025 \\
(0.003)\end{array}$ & $\begin{array}{l}-0.035 \\
(0.004)\end{array}$ \\
\hline
\end{tabular}

Notes: All entries in the table represent coefficients estimated from separate regressions. The regressions underlying column (1) use abortions per 1,000 live births by the state in which the procedure was performed. This cruder proxy was the only data available at the time of Donohue and Levitt (2001). The regressions underlying column (2) use abortions per 1,000 live births by the state of residence of the birth mother, data newly made available by the Alan Guttmacher Institute. Results in the top, middle, and bottom panel of the table correspond to specifications in Tables 4, 6, and 7 of Donohue and Levitt (2001). While our earlier paper provides a more complete description of the specifications used, essentially the top panel tests the impact of abortion legalization on overall crime across states, the middle panel narrows the focus to separate out the influence on the under- 25 
age cohorts that were born after abortion legalization, and the bottom panel links the abortion rates in a state at the time a particular cohort was born with the crime rate of that cohort over time. In all cases, the full set of covariates used in our earlier paper are included in the regressions (but not shown here). Standard errors, corrected for first-order serial correlation, are in parentheses. The top panel covers the period 1985-1997, while the second and third use the period 1985-1996. 
Table 2: Effective Abortion Rates for Early-Legalizing States versus the Rest of the United States Selected Years

\begin{tabular}{|l|l|l|l|l|}
\hline Effective abortion rate & 1982 & 1988 & 1994 & 1997 \\
\hline Early legalizers & 0.0 & 64.0 & 238.6 & 327.0 \\
\hline Rest of U.S. & 0.0 & 10.4 & 87.7 & 141.0 \\
\hline $\begin{array}{l}\text { Difference between early } \\
\text { legalizers and rest of U.S. }\end{array}$ & 0.0 & 53.6 & 150.9 & 186.0 \\
\hline
\end{tabular}

Notes: Early legalizing states are Alaska, California, Hawaii, New York, and Washington. These five states legalized abortion in late 1969 or 1970. In the remaining states, abortion became legal in 1973 after Roe $v$. Wade. The row labeled "Difference" is the difference in the effective abortion rate between early legalizers and the rest of the United States. The effective abortion rate is a proxy measure for the average exposure to abortion among potential criminals in a state and year (see footnote of the text for further discussion). Because the age distribution of criminals differs across crimes, the effective abortion rate also varies by crime. Values in the table are effective abortion rates for violent crime. The calculation of the effective abortion rate follows equation (1) in Donohue and Levitt (2001) and is based on the observed age distribution of national arrests for violent crime in 1985. Abortion data are from the Alan Guttmacher Institute. 
Table 3: The Impact of Early Abortion Legalization on Homicide

Comparison of cohorts born before and after 1970 in early legalizing and control states

\begin{tabular}{|c|c|c|c|c|c|c|c|}
\hline & \multicolumn{3}{|c|}{$\begin{array}{l}\text { Number of Homicides Committed in } \\
\text { Control States (legalize in 1973) } \\
\text { for Selected Ages and Birth Cohorts }\end{array}$} & \multicolumn{3}{|c|}{$\begin{array}{l}\text { Number of Homicides Committed in } \\
\text { Early Legalizers (legalize in 1970) } \\
\text { for Selected Ages and Birth Cohorts }\end{array}$} & $\begin{array}{l}\text { Diffs-in-diffs } \\
\text { estimate of } \\
\text { exposure to } \\
\text { legalized abortion }\end{array}$ \\
\hline & (1) & (2) & (3) & (4) & (5) & (6) & (7) \\
\hline Age & $\begin{array}{l}\text { Cohorts born } \\
\text { in } 1967,68,69 \\
\text { (unexposed) }\end{array}$ & $\begin{array}{l}\text { Cohorts born } \\
\text { in } 1971,72,73 \\
\text { (unexposed) }\end{array}$ & $\begin{array}{l}\% \text { change } \\
(71,72,73) \\
\text { vs }(67,68,69)\end{array}$ & $\begin{array}{l}\text { Cohorts born } \\
\text { in } 1967,68,69 \\
\text { (unexposed) }\end{array}$ & $\begin{array}{l}\text { Cohorts born } \\
\text { in } 1971,72,73 \\
\text { (exposed) }\end{array}$ & $\begin{array}{l}\% \text { change } \\
(71,72,73) \\
\text { vs }(67,68,69)\end{array}$ & $\begin{array}{l}\text { Column (6) } \\
\text { minus } \\
\text { column }(3)\end{array}$ \\
\hline$<15$ & 317 & 360 & $13.6 \%$ & 123 & 128 & $4.1 \%$ & $-9.5 \%$ \\
\hline $15-19$ & 4,268 & 7,050 & $65.2 \%$ & 1,829 & 3,020 & $65.1 \%$ & $-0.1 \%$ \\
\hline $20-26$ & 9,348 & 10,486 & $11.6 \%$ & 3,708 & 3,390 & $-8.6 \%$ & $-20.2 \%$ \\
\hline $\begin{array}{l}\text { All ages, } \\
0-26\end{array}$ & 13,983 & 17,846 & $28.0 \%$ & 5,660 & 6,538 & $15.5 \%$ & $-12.5 \%$ \\
\hline $\begin{array}{l}\text { Legal abortion } \\
\text { rate }\end{array}$ & 0 & 0 & ---- & 0 & 325 & ---- & ---- \\
\hline
\end{tabular}

Notes: Values reported in columns 1,2, 4, and 5 of the table are the raw number of homicides by state and year of birth for the named cohorts, based on Supplemental Homicide Report data. In early legalizing states, cohorts born after 1971 were exposed to legalized abortion. In the control states, none of the cohorts were exposed to an appreciable amount of legalized abortion (except for a small exposure to part of the 1973 birth cohort). Columns 3 and 6 report percent differences between the late and early cohorts. Column 7 presents the differences-in-differences estimate of exposure to legalized abortion. The bottom row of the table reports the legal abortion rate per 1,000 live births. 
Table 4: The Impact of Exposure to Legalized Abortion on Crime

Limiting the Sample to Cohorts Born 1968-1976

Excluding Early-Legalizing States

\begin{tabular}{|c|c|c|c|c|c|c|c|c|}
\hline \multirow{3}{*}{$\begin{array}{l}\text { Variable } \\
\text { Abortions per 1,000 live } \\
\text { births } \\
(\mathrm{x} 100)\end{array}$} & \multicolumn{8}{|c|}{ Dependent variable: } \\
\hline & \multicolumn{2}{|c|}{$\ln$ (violent crime arrests) } & \multicolumn{2}{|c|}{ ln (property crime arrests) } & \multicolumn{2}{|c|}{ ln (homicide arrests) } & \multicolumn{2}{|c|}{$\begin{array}{l}\text { In (homicide offenses) } \\
\text { using supplemental } \\
\text { homicide report data }\end{array}$} \\
\hline & $\begin{array}{l}-0.060 \\
(0.016)\end{array}$ & $\begin{array}{l}-0.061 \\
(0.015)\end{array}$ & $\begin{array}{l}-0.050 \\
(0.019)\end{array}$ & $\begin{array}{l}-0.044 \\
(0.018)\end{array}$ & $\begin{array}{l}-0.028 \\
(0.023)\end{array}$ & $\begin{array}{l}-0.035 \\
(0.029)\end{array}$ & $\begin{array}{l}-0.038 \\
(0.016)\end{array}$ & $\begin{array}{l}-0.048 \\
(0.020)\end{array}$ \\
\hline $\begin{array}{l}\text { State-age interactions } \\
\text { included as controls? }\end{array}$ & No & Yes & No & Yes & No & Yes & No & Yes \\
\hline Number of obs. & 3,738 & 3,738 & 3,743 & 3,743 & 3,124 & 3,124 & 3,129 & 3,129 \\
\hline $\mathrm{R}^{2}$ & .94 & .97 & .94 & .98 & .87 & .91 & .87 & .90 \\
\hline
\end{tabular}

Notes: The dependent variable is identified at the top of each column. Each entry in the table reflects the estimated coefficient on the variable abortions per 1,000 live births (by mother's state of residence) from a separate regression. All regressions include cohort, state, age, and year fixed effects. In addition, the even-numbered columns also control for include state-age interactions. Standard errors, corrected for first-order serial-correlation, are in parentheses. The number of observations varies across crime categories because of state-cohort-year observations in which crime data are missing or equal to zero. The cohorts included in the regression correspond to those in Joyce (2003) Table 5. The differences between this table and Joyce's Table 5 are (1) we use the abortion rate instead of a dummy for whether abortion is legal or not, (2) we include cohort effects to absorb nationwide changes in criminality across cohorts, (3) we use all of the years of available data for these cohorts (1985-1998), and (4) we allow for state-age interactions in some specifications. 
Figure 1: Change in Arrest Rates for offenders under 25, 1985-1998

States Ranked into three categories by the Effective Abortion Rate

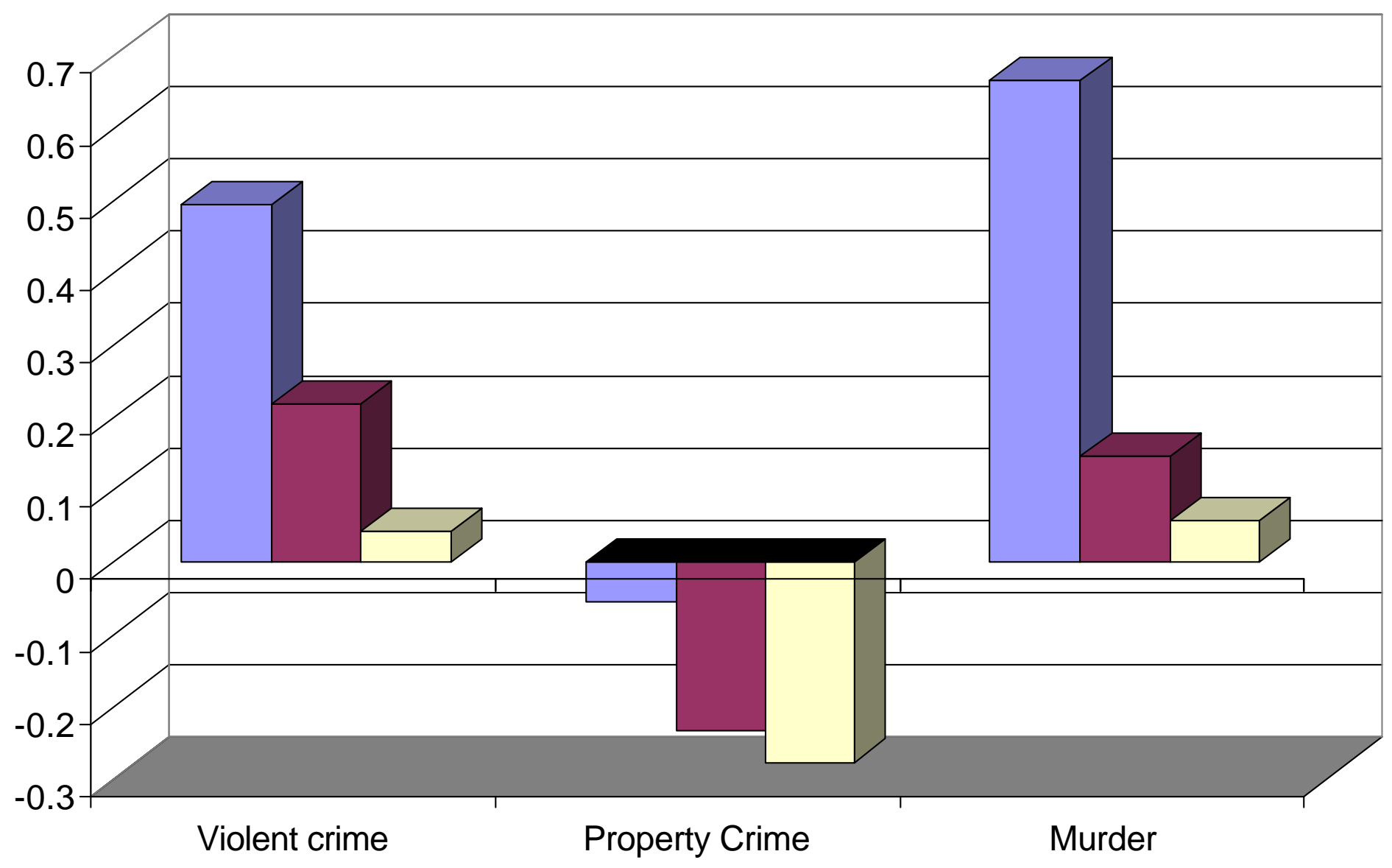

$\square$ Lowest

$\square$ Medium

$\square$ Highest 
Figure 2: Change in Arrest Rates for those over 25, 1985-1998

States Ranked into three categories by the Effective Abortion Rate

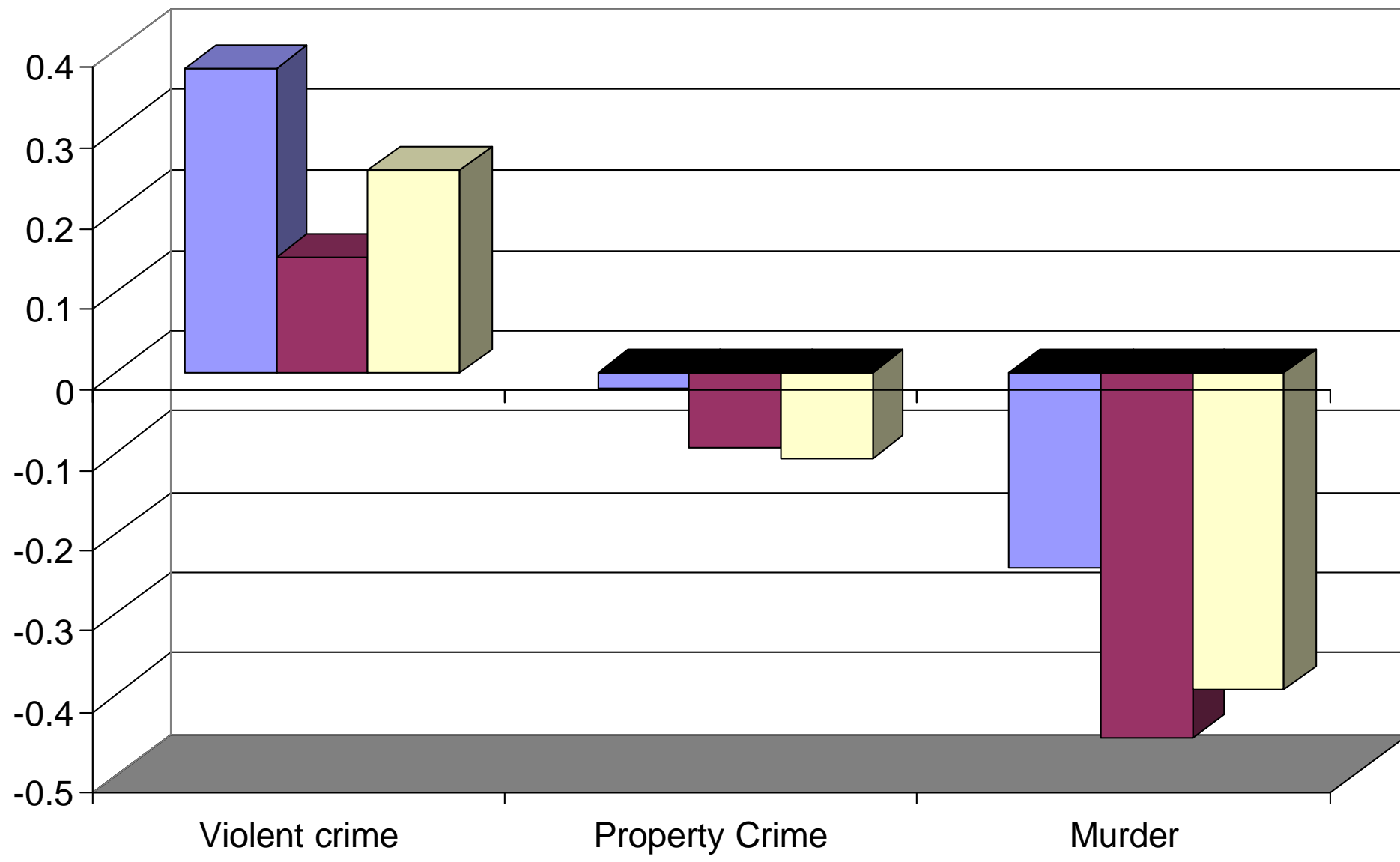

$\square$ Lowest

$\square$ Medium

$\square$ Highest 
Figure 3: Drug-Related Homicide Rates for 5 States Legalizing Abortion Early and for the Rest of the United States (1976-1999)

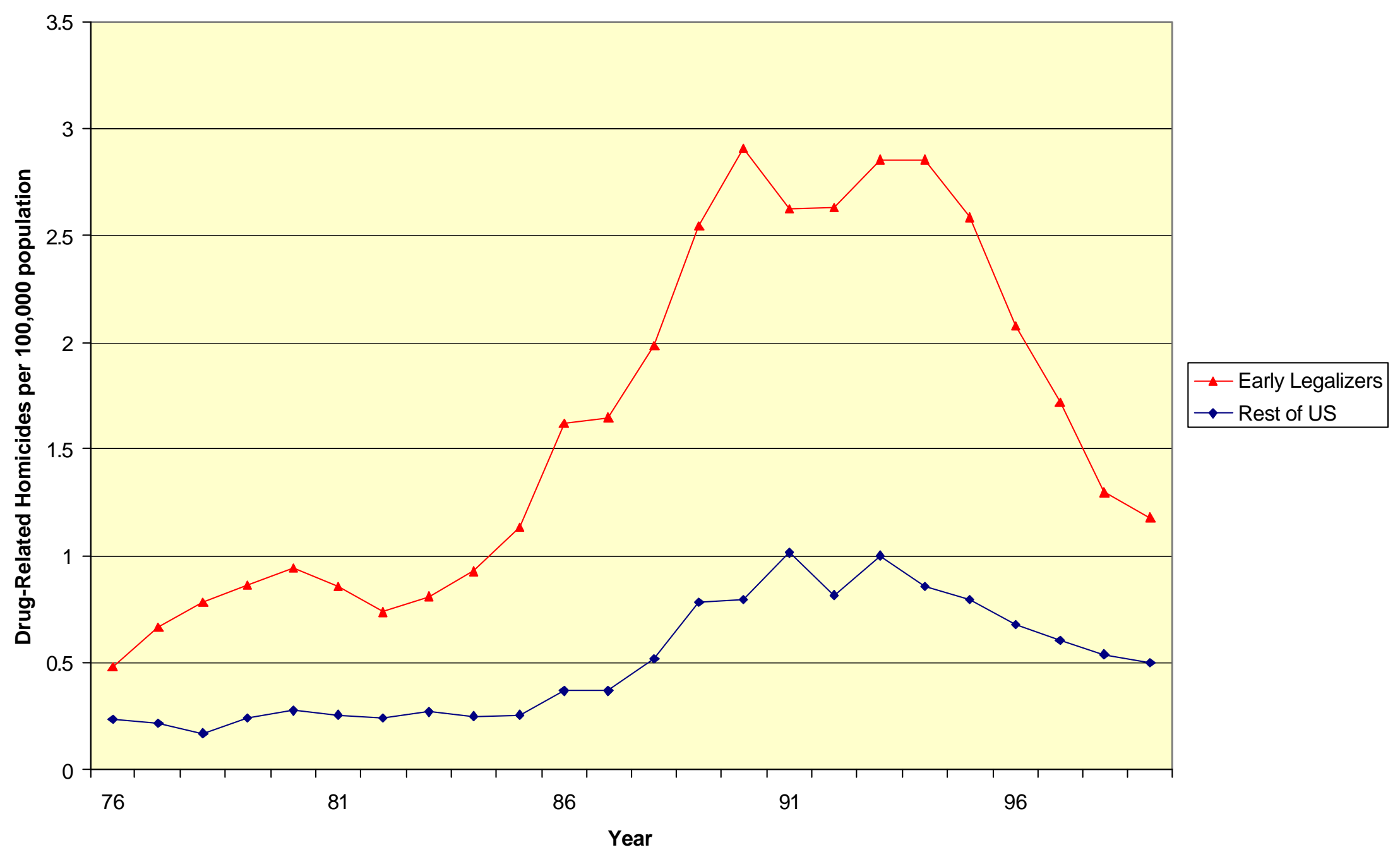


